\title{
Effect of a novel 5-lipoxygenase activating protein inhibitor, BAYx 1005, on asthma induced by cold dry air
}

Andrew R Fischer, Mitchell A Rosenberg, Miriam Roth, Marlene Loper, Steven Jungerwirth, Elliot Israel

\begin{abstract}
Background - Leukotrienes have been implicated in the mediation of airway obstruction induced by hyperventilation of cold dry air in asthmatic subjects. The effect of a novel inhibitor of 5-lipoxygenase activating protein, BAYx 1005, on the bronchospastic response to cold dry air hyperventilation was investigated in asthmatic patients.

Methods - After a screening cold dry air hyperventilation challenge to document cold air responsiveness, 16 asthmatic subjects (baseline forced expiratory volume in one second $\left(\mathrm{FEV}_{1}\right)>\mathbf{6 0 \%}$ of predicted) underwent cold air challenge three hours after receiving $750 \mathrm{mg}$ of BAYx 1005 or placebo using a randomised, double blind, crossover design. Leukotriene synthesis inhibition was estimated by measuring the concentration of leukotriene $B_{4}$ in whole blood stimulated with calcium ionophore A21387.
\end{abstract}

Results - Treatment with BAYx 1005 produced a $34 \%(95 \%$ CI 11 to 63) increase in the amount of cold air minute ventilation required for a $10 \%$ decrease in $\mathrm{FEV}_{1}$ $\left(\mathbf{P D}_{10} \dot{\mathbf{V}}\right.$ E) compared with placebo (mean (SE) $37.6(1.12) 1 / \mathrm{min}$ compared with 28.0 (1.13) $1 / \mathrm{min}, \mathrm{p}<0.006)$. The $\mathbf{P D}_{20} \dot{\mathbf{V}}_{\mathrm{E}}$ increased $19 \%(95 \%$ CI 8 to 31$)$ after treatment with BAYx 1005 compared with placebo $(57.3(1.10) 1 / \mathrm{min}$ versus $48.1(1.10)$ $1 / \mathrm{min}, \mathrm{p}<0.002)$. Treatment with BAYx 1005 produced a $15.4 \%$ decrease in ionophorestimulated $\mathrm{LTB}_{4}$ production, while treatment with placebo produced a $7.1 \%$ increase in ex vivo LTB $_{4}(p<0.02)$.

Conclusions - Treatment with BAYx 1005, a novel inhibitor of leukotriene synthesis, produced a significant blunting of cold dry air responsiveness consistent with the hypothesis that leukotrienes mediate part of the bronchoconstriction induced by hyperventilation of cold dry air.

(Thorax 1997;52:1074-1077)

Keywords: asthma, leukotrienes, isocapnic hyperventilation.

Most asthmatic subjects experience airway narrowing after appropriate levels of exercise or the eucapnic hyperventilation of cold dry air. The precise mechanism of this effect, including the role of biochemically active mediators, is unknown. The cysteinyl leukotrienes $\left(\mathrm{LTC}_{4}\right.$, $\mathrm{LTD}_{4}$, and $\mathrm{LTE}_{4}$ ) are potent mediators of bronchoconstriction that possess proinflammatory properties. They have been implicated in the pathobiology of asthma, including asthma induced by cold dry air. ${ }^{12}$

The first dedicated step in the biosynthesis of the cysteinyl leukotrienes is the introduction of molecular oxygen into arachidonic acid which results in the formation of 5-hydroperoxyeicosatetraenoic acid, which in turn is further metabolised to leukotriene $\mathrm{A}_{4}$; both reactions are catalysed by the enzyme 5-lipoxygenase (5-LO) in the presence of 5 -LO activating protein (FLAP). ${ }^{1}$ Medications that antagonise cysteinyl leukotriene receptors and inhibitors of 5-LO have been shown to blunt the bronchospasm elicited by exercise, allergen, or aspirin..$^{3-5}$ Bronchospasm induced by cold dry air has been blunted by inhibitors of 5LO and antagonists of cysteinyl leukotriene receptors. ${ }^{26}$ FLAP inhibitors have been shown to blunt antigen-induced responses ${ }^{78}$ but have not been tested against the stimulus of cold dry air. We investigated the potency of a novel inhibitor of FLAP, BAYx 1005, on the response to bronchoprovocation with cold dry air.

\section{Methods}

SUBJECTS

Asthmatic subjects aged 18-60 with baseline forced expiratory volume in one second $\left(\mathrm{FEV}_{1}\right)$ $>60 \%$ of predicted and a $>20 \%$ decrease in $\mathrm{FEV}_{1}$ after a screening challenge with cold dry air were eligible to participate. Each subject was a non-smoker ( $<5$ pack years) previously treated with inhaled $\beta_{2}$ agonists alone. All forms of corticosteroids were prohibited for eight weeks and disodium cromoglycate or nedocromil use was prohibited for two weeks before entry to the study. All subjects gave their written informed consent to participate in the protocol which was approved by the Committee on Clinical Investigations of the Beth Israel Hospital.

STUDY DESIGN

Subjects received a single oral dose of $750 \mathrm{mg}$ BAYx 1005 or placebo using a randomised, 

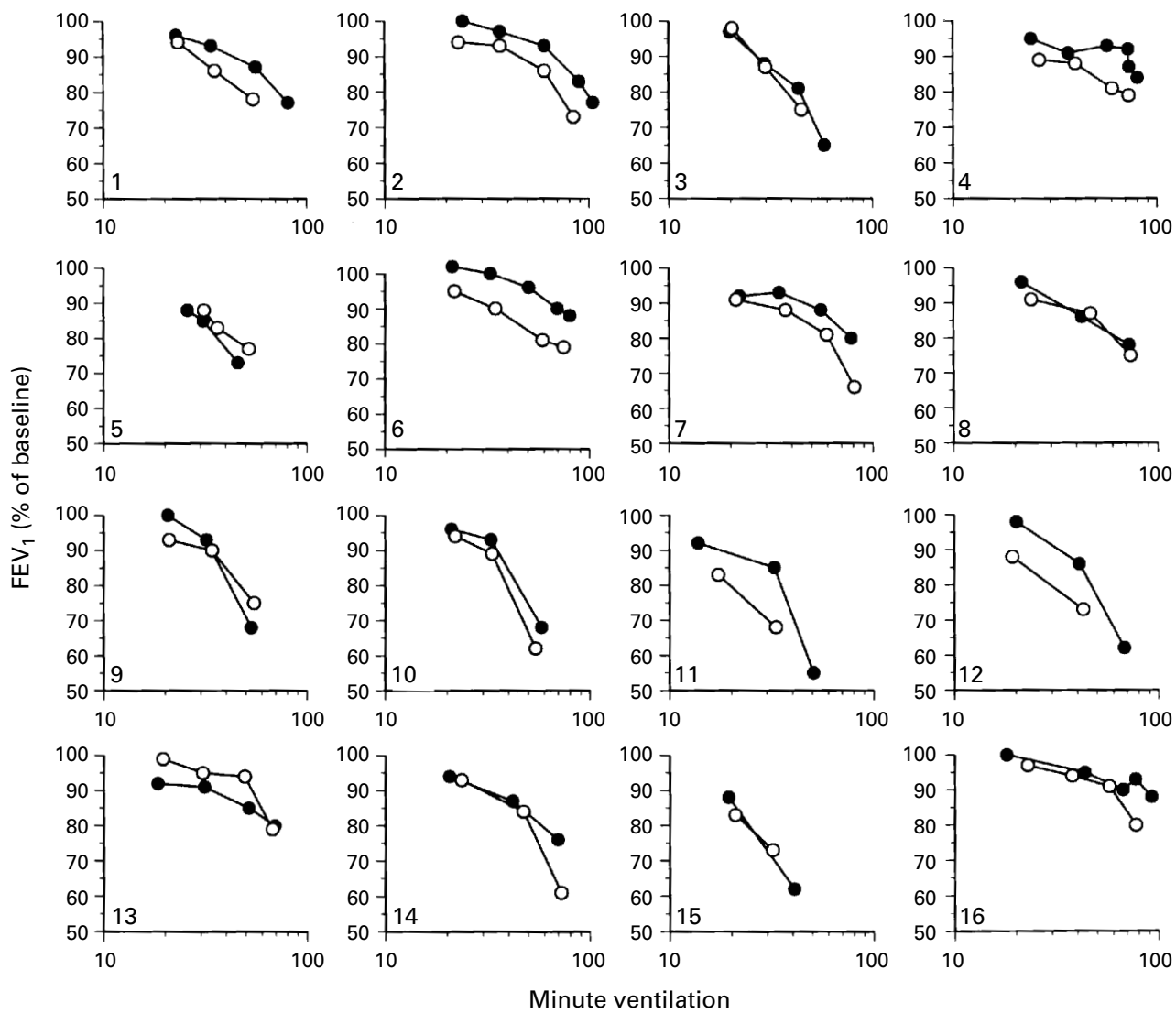

Figure 1 Cold air challenge dose-response curve for each subject. The $F E V_{1}$ as a percentage of the prechallenge FEV $V_{1}$ plotted for each subject against the amount of cold dry air minute ventilation. $\mathbf{O}=B A Y x 1005, \bigcirc=$ placebo.

double blind, crossover design, followed three hours later by cold air challenge. The $\mathrm{FEV}_{1}$ was measured every 30 minutes after BAYx 1005 dosing until the start of the cold air challenge and every 15 minutes for one hour after completion of the cold air challenge. An average of nine days (range 7-21) later the subjects returned, crossed over to the alternative treatment, and underwent the identical challenge protocol. The techniques for performing the cold air challenges have been described previously. ${ }^{2}$ Challenges for individual subjects were performed at the same time of day. The amount of cold air minute ventilation needed to produce a $10 \%$ or $20 \%$ decrease in $\mathrm{FEV}_{1}$ was determined by linear interpolation from the $\log _{10}$ dose-response curves. The time for the $\mathrm{FEV}_{1}$ to return to within $5 \%$ of baseline was obtained by linear interpolation from the $\mathrm{FEV}_{1}$ data obtained after cold air challenge.

The ability of BAYx 1005 to inhibit eicosanoid production was estimated via ex vivo measurement of $\mathrm{LTB}_{4}$ and thromboxane $\mathrm{B}_{2}$ $\left(\mathrm{TxB}_{2}\right)$ production in whole blood stimulated with calcium ionophore A23187. Blood was drawn immediately before ingestion of BAYx 1005 and three hours later (just prior to the cold air challenge). Aliquots were stimulated with calcium ionophore A21387 $(50 \mu \mathrm{M})$ and incubated for 30 minutes. Serum was collected and stored at $-80^{\circ} \mathrm{C}$ until assay for $\mathrm{LTB}_{4}$ (assay courtesy of Dr R Müller-Peddinghaus,
Bayer AG) and thromboxane $\mathrm{B}_{2}$ using standard methodology.

Plasma levels of BAYx 1005 were measured in unstimulated samples using a standard HPLC assay. All the eicosanoid data from one subject (no. 15) were excluded because $\mathrm{LTB}_{4}$ was not detected in stimulated blood three hours after ingestion of BAYx 1005; very low levels of $\mathrm{TxB}_{2}$ were detected in that specimen as well.

ANALYSIS OF DATA

All cold air challenge data analyses were performed on $\log _{10}$ transformed data. Cold air challenge data are reported as geometric means (standard error of the geometric mean) and analysed with a standard crossover ANOVA. An analysis of covariance (ANCOVA) using the prechallenge $\mathrm{FEV}_{1}$ (0-3 hours after drug ingestion) as a covariant was performed to adjust for the effect of prechallenge bronchodilation. Continuous variables were reported as means with a range or $95 \%$ confidence interval. A paired $t$ test was used to detect differences between groups. No sequence or period effects were found so all data were analysed together.

\section{Results}

Eighteen men of mean age 27 years (range 19-41) were enrolled and 16 completed the 
study. Two were excluded because of illnesses occurring before completion of the double blind phase; both subjects had received placebo. The mean baseline $\mathrm{FEV}_{1}$ was 3.761 (range $2.60-5.21$ ) or $86 \%$ predicted (range 60-114\%). The mean (SE) baseline $\mathrm{PD}_{20} \mathrm{VE}$ was 51.7 (1.07) 1 (range 33.6-87.0).

The mean plasma level of BAYx 1005 three hours after ingestion was $9.7 \mu \mathrm{g} / \mathrm{ml}$ (range 3.021.1). BAYx 1005 was not detected in the plasma of any subject before dosing or three hours after placebo ingestion. There was no significant difference in $\mathrm{FEV}_{1}$ before drug administration on the placebo challenge day compared with the BAYx 1005 challenge day (3.55 1 (2.63-4.48) and 3.571 (2.55-4.54), respectively. The $\mathrm{FEV}_{1}$ increased 0.311 three hours after BAYx 1005 ingestion compared with 0.151 three hours after placebo ingestion, a difference of 0.161 (95\% CI, 0.06 to 0.26$)$ $(\mathrm{p}<0.009)$.

The cold air challenge data of individual subjects are shown in fig 1 . The $\mathrm{PD}_{10} \dot{\mathrm{V}} \mathrm{E}$ increased by $34 \%$ (95\% CI 11 to 63 ) after treatment with BAYx 1005 compared with placebo (37.6 (1.12) versus 28.0 (1.13) $1 / \mathrm{min}$, $\mathrm{p}<0.006)$, while the $\mathrm{PD}_{20} \mathrm{VE}$ increased by $19 \%$ (95\% CI 8 to 31 ) after treatment with BAYx 1005 compared with placebo $(57.3$ (1.10) versus $48.1(1.10) 1 / \mathrm{min}, \mathrm{p}<0.002)$. This increase in $\mathrm{PD}_{20} \dot{\mathrm{V}} \mathrm{E}$ after BAYx 1005 was significantly different from that after placebo, despite prechallenge bronchodilation $\quad(p<0.04$, ANCOVA). Since cold dry air hyperventilation was increased until each subject achieved at least a $20 \%$ fall in $\mathrm{FEV}_{1}$, subjects achieved nearly the same maximal decline in $\mathrm{FEV}_{1}$ after the challenge $-74 \%$ of baseline after BAYx 1005 compared with $73 \%$ of baseline after placebo. However, when subjects were treated with BAYx 1005 the $\mathrm{FEV}_{1}$ returned toward baseline more rapidly than with placebo. The $\mathrm{FEV}_{1}$ reached $95 \%$ of baseline 22 minutes (range 8-60) after cold air challenge on the day of treatment with BAYx 1005 compared with 36 minutes (range 15-60) after cold air challenge on the day of treatment with placebo; hence the $\mathrm{FEV}_{1}$ was within $5 \%$ of the prechallenge $\mathrm{FEV}_{1} 14$ minutes (95\% CI 6 to 22 ) faster after BAYx 1005 treatment than after placebo $(\mathrm{p}=0.002)$.

BAYx 1005 inhibited the change in ex vivo calcium ionophore-stimulated $\mathrm{LTB}_{4}$ production compared with placebo $(\mathrm{p}<0.02)$. Treatment with BAYx 1005 produced a $15.4 \%$ decrease in whole blood ex vivo calcium ionophore-stimulated $\mathrm{LTB}_{4}$ production. In contrast, on the day subjects received placebo there was a $7.1 \%$ increase in whole blood ex vivo calcium ionophore-stimulated $\mathrm{LTB}_{4}$ production.

No significant adverse events related to BAYx 1005 occurred during the study.

\section{Discussion}

Exercise and cold dry air hyperventilation produce airway cooling and drying which result in bronchoconstriction in most asthmatic subjects. The biomolecules involved in mediating these effects have not been well defined. Our previous studies have shown that treatment with inhibitors of 5-lipoxygenase or cysteinyl leukotriene receptor antagonists blunts the bronchospastic response to the eucapnic hyperventilation of cold dry air. ${ }^{26}$ The current data show blunting of cold air-induced bronchospasm by an agent that inhibits leukotrienes by a third mechanism of action - inhibition of FLAP. ${ }^{9}$ These results provide further evidence that the salutary effects of "antileukotriene" drugs on cold air hyperventilation relate to their effects on leukotrienes rather than to some other non-specific bronchodilating effects of those agents. While we did observe some bronchodilation, our analysis shows that the effect of BAYx 1005 was independent of the small degree of prechallenge bronchodilation. It is interesting to compare the degree of protection afforded by BAYx 1005 against cold air challenge with that of other agents active against leukotriene formation or action. BAYx 1005 increased the amount of cold dry air hyperventilation needed to produce a $10 \%$ and $20 \%$ decrease in $\mathrm{FEV}_{1}\left(\mathrm{PD}_{10}\right.$ and $\left.\mathrm{PD}_{20}\right)$ by $34 \%$ and $19 \%$, respectively. Its effects approximated that of the leukotriene receptor antagonist LY171883 which produced a $22 \%$ increase in $\mathrm{PD}_{20} \mathrm{VE}$ after two weeks of treatment at a dose of $600 \mathrm{mg}$ twice daily. ${ }^{6}$ However, the degree of inhibition produced was less than a single $800 \mathrm{mg}$ dose of the 5-LO inhibitor zileuton, which increased the $\mathrm{PD}_{10} \mathrm{VE}$ by $45 \%$. $^{2}$ The reasons for the lesser magnitude of protection with BAYx 1005 are unclear but may include poor tissue penetration, differences in protein binding characteristics of BAYx 1005, or intrinsic differences in drug potency.

Considering the physiological effects of BAYx 1005, we believe that the small degree of ex vivo inhibition of leukotriene synthesis observed was due in part to the experimental conditions under which ionophore stimulation occurred. Our studies were carried out at $\mathrm{pH}$ 7.4 with $50 \mu \mathrm{M}$ ionophore. Studies carried out two hours after a single $500 \mathrm{mg}$ dose of BAYx 1005 , at a time drug levels were similar to those seen in our study but at $\mathrm{pH} 7$ using an ionophore concentration of $5 \mu \mathrm{M}$, showed $81 \%$ inhibition of $\mathrm{LTB}_{4}$ production compared with $33 \%$ inhibition of ionophore-stimulated $\mathrm{LTB}_{4}$ production at $\mathrm{pH} 7.4$ using an ionophore concentration of $30 \mu \mathrm{M}$ (data on file, Bayer AG).

In summary, using a FLAP inhibitor our data provide further confirmation that 5-lipoxygenase products play a part in mediating the airway narrowing that occurs after hyperventilation of cold dry air. Since leukotrienes only appear to play a partial role in mediating this bronchospastic response, the clinical usefulness of BAYx 1005 may need to be evaluated further in larger studies of spontaneous asthma.

This study was supported by a grant from Bayer Corporation (formerly Miles Inc) and by NIH Grant HL-T32-07633.

1 Henderson WR Jr. The role of leukotrienes in inflammation. Ann Intern Med 1994;121:684-97.

2 Israel E, Dermarkarian R, Rosenberg M, Sperling R, Taylor G, Rubin P, et al. The effects of a 5-lipoxygenase inhibito on asthma induced by cold, dry air. N Engl f Med 1990; 323:1740-4 
3 Finnerty JP, Wood-Baker R, Thomson H, Holgate ST. Role of leukotrienes in exercise-induced asthma. Inhibitory effect of ICI 204,219, a potent leukotriene D4 receptor antagonist. Am Rev Respir Dis 1992;145:746-9.

4 Taylor IK, O'Shaughnessy KM, Fuller RW, Dollery CT. Effect of cysteinyl-leukotriene receptor antagonist ICI 204, 219 on allergen-induced bronchoconstriction and airway hyperreactivity in atopic subjects. Lancet 1991;337:690-4.

5 Israel E, Fischer AR, Rosenberg MA, Lilly CM, Callery JC, Shapiro J, et al. The pivotal role of 5-lipoxygenase products in the reaction of aspirin-sensitive asthmatics to aspirin. Am Rev Respir Dis 1993;148:1447-51.

6 Israel E, Juniper EF, Callaghan JT, Mathur PN, Morris MM, Dowell AR, et al. Effect of a leukotriene antagonist, LY171883, on cold air-induced bronchoconstriction in asthmatics. Am Rev Respir Dis 1989;140:1348-53.
7 Friedman BS, Bel EH, Buntinx A, Tanaka W, Han YH, Shingo S, et al. Oral leukotriene inhibitor (MK-886) blocks allergen-induced airway responses. Am Rev Respir Dis 1993 147:839-44.

8 Diamant Z, Timmers MC, van der Veen H, Friedman BS, DeSmet M, Depre M, et al. The effect of MK-0591, a nove 5-lipoxygenase activating protein inhibitor, on leukotriene biosynthesis and allergen-induced airway responses in asthmatic subjects in vivo. 7 Allergy Clin Immunol 1995;95: $42-51$.

9 Hatzelmann A, Fruchtmann R, Mohrs KH, Raddatz S, Muller-Peddinghaus R. Mode of action of the new selective leukotriene synthesis inhibitor BAYx $1005\{(\mathrm{R})-2-[4-$-(quinolin-2-yl-methoxy)phenyl]-2-cyclopentyl acetic acid; and
structurally related compounds. Biochem Pharmacol 1995; 45:101-11. 